\title{
Professores de escolas primárias na França e ensino de Geografia: saberes escolares disciplinares e práticas de ensino
}

\author{
Thierry Philippot*
}

\section{Resumo}

A França, como outros Estados-nação, desencadeou, há cerca de 20 anos, uma profunda reforma no seu sistema de ensino, que se traduziu, particularmente, por uma redefinição dos objetivos da escola. Objetivos esses que visam à aquisição de conhecimentos básicos e de habilidades que oportunizem aos alunos sucesso na escola e sua inclusão na sociedade. A questão da transmissão e da apropriação dos conhecimentos das disciplinas escolares é, portanto, fundamental para os docentes generalistas da escola primária. Mas importa saber o que acontece no cotidiano da sala de aula, quais as relações que os docentes estabelecem com os saberes e as disciplinas a serem ensinados e se o processo de transmissão e apropriação organiza suas práticas de ensino. A análise da atividade didática dos docentes generalistas, a partir de gravações de vídeo de aulas de Geografia e de entrevistas de autoconfrontação demonstra uma forma de marginalização dos saberes escolares disciplinares nas práticas de ensino. 0 processo de transmissão e apropriação dos conhecimentos disciplinares parece, assim, não estruturar essas práticas.

\section{Palavras-chave}

práticas de ensino; escola primária; saberes escolares disciplinares; didática da Geografia; análise do trabalho.
* Maître de conférences en Sciences de l'Education no Instituto Universitário de Formação dos Mestres, Université de Reims Champagne Ardenne, França. Membro do Laboratório de Estudo e Pesquisa sobre as Profissionalizações (LERP). Thierry.philippot@ univ-reims.fr 


\title{
Primary school teachers and the teaching of geography in France: disciplinary school knowledge and teaching practices
}

\begin{abstract}
Twenty years ago France, along with other countries, started to implement in-depth educational reforms which led to a redefinition of school objectives. Such objectives aim for the acquisition of a set of basic key knowledge and competencies which will enable students to succeed in school and be inserted in society. Therefore, the transmission-appropriation of subject knowledge has become a key issue for generalist primary school teachers. However, what is the situation like in the classroom? What kind of links tie teachers, knowledge and school subjects? Are their teaching practices organised by the transmission-appropriation process? Video recordings of geography lessons and interviews in crossed self-confrontation mode have been used to study the didactic activity of generalist teachers. The analyses show that there is some marginalisation of disciplinary school knowledge in teaching practice. The transmission-appropriation process plays a minor role in the organisation of teaching practices.
\end{abstract}

Key words teaching practice; primary school; geography didactics; work analysis. 
A França, como outros inúmeros Estados-nação, desencadeou há cerca de 20 anos, uma profunda reforma no seu sistema de ensino, a qual se traduziu, particularmente, por uma redefinição dos objetivos da escola. Assim, "a escola primária deve transmitir, e levar cada aluno a adquirir, os conhecimentos e as competências fundamentais que serão necessárias a ter êxito nos estudos colegiais e muito além deles" (M.E.N., 2008). Desde então, pode-se considerar a questão dos saberes escolares, da sua transmissão pelos docentes e da sua apropriação pelos alunos, assim como a relação desses docentes com os saberes disciplinares, como dimensões essenciais da profissionalidade dos docentes generalistas da escola primária. Mas o que acontece no cotidiano da sala de aula? Qual é o lugar e o papel dos saberes disciplinares nas práticas de ensino? Quais são as características dos conhecimentos mobilizados pelos professores? Qual a relação que estes estabelecem com as disciplinas a serem ensinadas? 0 processo de transmissão e apropriação de conhecimentos escolares disciplinares organiza as práticas de ensino numa disciplina como a Geografia?

\section{0 docente da escola primária: um mestre "generalista e expert"}

$\mathrm{Na}$ França, os docentes da escola primária são docentes polivalentes. Esta dimensão específica do trabalho dos docentes do primeiro grau, qualificada de polivalência, é uma construção histórica (Baillat, 2001). Progressivamente, o docente da escola primária se tornou polivalente-generalista, isto é, um mestre capaz de ensinar todas as disciplinas previstas pelo currículo da escola primária. Esta "profissionalização antiga” (Lang, 1999) permitiu aos docentes, durante muito tempo, responder às demandas da sociedade de forma satisfatória.

No entanto, a partir dos anos 1960, "na maioria dos países capitalistas 'avançados', as sociedades e as instituições escolares foram submetidas a transformações importantes" (Maroy, 2006, p. 112). Nesse contexto, aquela “profissionalização antiga” já não permite aos docentes responder de forma satisfatória às várias demandas que, doravante, se impõem à escola. As críticas se multiplicam desde então, "elas visam à instituição escolar, ao conteúdo do ensino e aos métodos pedagógicos” (Blat Gimeno, 1984, p. 12). Colocam-se em questão a escola, seus docentes e a capacidade destes de assegurar o êxito dos alunos.

Como resposta a essas críticas e às diversas demandas sociais que pesam sobre a escola e sobre os docentes, uma intenção social de profissionalização (Wittorsky, 
2008) vem sendo desenvolvida, no nível das esferas dirigentes, a partir dos anos 1980. Ela carrega em si uma nova profissionalidade para os docentes, impondo-lhes a figura de mestre expert. Dessa maneira, os textos oficiais apresentam o professor da escola primária, ao mesmo tempo, como um professor generalista, mas também como um expert, especialista no ensino de todas as disciplinas, capaz de assegurar, ao longo de um ano escolar, a aprendizagem efetiva dos seus alunos, pois ele domina a didática das suas disciplinas (M.E.N., 2005). Esta figura paradoxal, garantia de eficácia para o Ministério, coloca no centro da profissionalidade dos docentes os processos de transmissão e apropriação dos conteúdos disciplinares. Diante de tais prescrições, esses conteúdos escolares deveriam estruturar fortemente as práticas de ensino.

\section{A Geografia na escola primária francesa}

A escola primária francesa está organizada em três ciclos¹, mas somente a partir do $3^{0}$ ciclo as disciplinas escolares: Matemática, Francês, Ciências, História, Geografia, etc. estruturam os ensinamentos e também as aprendizagens a serem realizadas pelos alunos. Assim, no $3^{\circ}$ ciclo, o currículo de Geografia tem como objetivo:

descrever e entender como os homens vivem e organizam seus territórios. Os sujeitos estudados se situam, em primeiro lugar, na escala local e nacional; eles visam identificar e conhecer as principais características geográficas da França no contexto europeu e mundial (M.E.N., 2008, p. 25).

Além das prescrições, o ensino da Geografia tem-se mostrado bem presente nas salas de aula. De fato, trabalhos de pesquisa como os de Audigier (1999), Audigier e Tutiaux-Guillon (2004), Baillat $(2001,2003)$ e um estudo da Inspection Générale de l'Éducation Nationale (2005) atestam uma presença relativamente forte do ensino da Geografia nas salas de aula do $3^{0}$ ciclo da escola elementar.

\section{Um duplo olhar sobre as práticas de ensino}

Nas nossas pesquisas empíricas, esse duplo

1. Cada ciclo corresponde a vários anos de escola: $1^{0}$ ciclo (alunos com idades entre 3 e 5 anos); $2^{0}$ ciclo (alunos com idades entre 6 e 7 anos); e $3^{0}$ ciclo, que corresponde às series de $\mathrm{CE}_{2}, \mathrm{CM}_{1} \mathrm{eCM} 2$ (alunos com idades entre 8 e 11 anos). olhar articula a didática da Geografia e as contribuições da análise do trabalho. 0 ponto de vista didático considera a análise das práticas de ensi- 
no a partir da questão dos processos de ensino-aprendizagem dos conteúdos nas suas especificidades disciplinares. Nessa perspectiva, uma pesquisa sobre o ensino da Geografia na escola primária (Audigier; Tutiaux-Guillon, 2004) coloca em evidência que as práticas de ensino observadas se apoiam essencialmente em um "modelo tradicional" de ensino, que se baseia na transmissão de saberes muito fatuais. Apesar das evoluções epistemológicas que marcaram a Geografia universitária e das diversas orientações oficiais que supunham evoluções importantes nas práticas de ensino, a Geografia ensinada, tal como revelada por esta pesquisa, aparece ainda fortemente marcada pela estagnação.

Este estudo, como outros conduzidos sobre a didática da Geografia, baseada essencialmente nas práticas de ensino declaradas, nas observações de grupos, considera o docente como um docente genérico. Sendo assim, a relação deste com os conteúdos escolares que ele deve ensinar é pouco considerada. No entanto, resultados de pesquisas realizadas no contexto francês (Baillat, 2001, 2003; Niclot; Philippot, 2008), como aqueles de trabalhos quebequenses (Lenoir et al., 2000), conduzem a uma constatação idêntica: no contexto de polivalência, os professores mantêm uma relação ambígua com as disciplinas escolares a serem ensinadas. Esses resultados evidenciaram a necessidade de levar em conta o docente e sua subjetividade no estudo sobre as práticas de ensino.

A análise do processo de trabalho do docente se desenvolveu a partir dos aportes teóricos e metodológicos da psicologia do trabalho e da ergonomia. Ela toma como elemento central o profissional - aqui, o professor -, o que ele é e o que ele faz nas situações de trabalho com as quais é confrontado cotidianamente, e abre um amplo espaço à sua subjetividade. Nessa perspectiva, a "atividade" do profissional é definida como "um diálogo dinâmico entre sujeito e tarefa" (Yvon; Clot, 2004, p. 14). Esta noção de atividade expressa "a tensão que o sujeito vive entre o prescrito e o realizado e os recursos que ele deve mobilizar, muitas vezes de maneira conflituosa, para cumprir aquilo que tem para fazer" (Amigues, 2009, p.12). Assim, a atividade de um profissional não se reduz "ao que é realizado", ao que é diretamente observável, mas diz respeito também "ao que não se faz e ao que procura ser feito sem conseguir" (Clot et al., 2000, p. 2). Portanto, para a análise do trabalho docente, é importante não limitar a prática do ensino a sua única dimensão observável, mas também considerar que "uma ação sempre se desenha sobre um pano de fundo que a ultrapassa" (Durand, 2009, p. 840). 
O ponto de vista didático é um ponto de vista extrínseco, que pode conduzir à análise daquilo que faz o docente - sua prática de ensino -, em termos de variações em relação a uma norma, de "defeito, incompreensão, incompetência” (Amigues, 2003, p. 9). Já o ponto de vista da análise do trabalho é intrínseco, pelo fato de que ele concede todo seu espaço ao sujeito. Adotar tal ponto de vista permite, em parte, ter acesso ao sentido que o profissional dá a sua prática. Ele autoriza uma análise desta última em termos de "escolhas, acertos, incertezas, decisões, riscos e investimentos subjetivos para fazer o melhor possível na tensão entre o prescrito e o real" (Amigues, 2003, p. 9). Tal abordagem pode evitar os olhares normativos, muitas vezes dirigidos ao que fazem os professores.

As práticas de ensino são objetos complexos, e o seu estudo confronta o pesquisador com "fatos humanos ou sociais [...] portadores de significados veiculados por atores (homens, grupos, instituições...), que são partes integrantes de uma situação inter-humana" (Mucchielli, 2009, p.24). Assim, acreditamos que este quadro de referência, que associa dois pontos de vista, tem importância heurística. É neste âmbito que nos propomos analisar as práticas de ensino em Geografia na escola primária e, assim, responder às nossas questões de pesquisa.

\section{Metodologia da pesquisa}

Numa perspectiva compreensiva e a fim de nos situarmos o mais próximo possível do trabalho efetivo dos professores, mesmo admitindo "que uma parte da atividade permanecerá, apesar de tudo, misteriosa" (Pastré, 2008, p. 15), escolhemos uma metodologia baseada em gravações de sessões de aulas. Além disso, para permitir ao ator expressar-se sobre sua própria prática (significado, escolha, etc.), realizamos entrevistas de autoconfrontação simples (Clot et al., 2000). Trata-se de uma situação de diálogo entre o docente e o pesquisador, na qual o docente "é levado a comentar sua própria atividade, reproduzida pelo vídeo” (Goigoux, 2002, p. 127). No momento das entrevistas, o pesquisador propõe ao professor "episódios"2

2. Esses "episódios" correspondem aos momentos de sala de aula nos quais, do ponto de vista do pesquisador (ponto de visto didático), algo importante está acontecendo.

3. Esta pesquisa contou com a participação de nove professores voluntários do $3^{0}$ ciclo de escolas elementares em diversos contextos profissionais. selecionados antecipadamente e lhe oferece também a possibilidade de comentar qualquer outro aspecto da sua aula.

O dispositivo de coleta dos dados, idêntico para os nove professores ${ }^{3}$, compreende, então, a gravação por vídeo de uma aula proposta pelo 
professor e, após algumas semanas ${ }^{4}$, uma entrevista de autoconfrontação. 0 conjunto do material discursivo constituído pelas nove gravações em vídeo e pelas entrevistas de autoconfrontação foi transcrito. Diante da quantidade de informações a serem tratadas, procedemos a uma análise dupla desse material: uma análise textual, realizada com a ajuda do programa ALCESTE, e uma análise de conteúdo. Para construir nossas categorias de análise, numa perspectiva didática, decidimos apoiar-nos no conceito de disciplina escolar (Audigier, 1993; Chervel, 1988). A grade de análise elaborada, como apresentada abaixo, na Figura 1, comporta quatro categorias principais: os conteúdos disciplinares, as tarefas, os objetos mobilizados e o conhecimento da disciplina. Cada uma dessas categorias foi subdividida em "subconjuntos".

\section{Figura 1 - Categorização didática dos enunciados}

\begin{tabular}{|c|c|c|}
\hline CATEGORIAS & \multicolumn{2}{|l|}{ SUBCONJUNTOS } \\
\hline \multirow{3}{*}{ A. Conteúdos disciplinares } & \multirow{2}{*}{ A.1 Saberes disciplinares } & A.1.1 Conceitos; noções \\
\hline & & A.1.2 Fatos \\
\hline & \multicolumn{2}{|l|}{ A.2 Habilidades disciplinares } \\
\hline \multirow{2}{*}{ B. Tarefas } & \multicolumn{2}{|l|}{ B.1 “Exercícios específicos” } \\
\hline & \multicolumn{2}{|l|}{ B.2 "Rituais didáticos" } \\
\hline \multirow{2}{*}{ C. Objetos } & \multicolumn{2}{|l|}{ C.1 Suportes didáticos } \\
\hline & \multicolumn{2}{|l|}{ C.2 Recursos didáticos } \\
\hline D. Conhecimento da discipli & & \\
\hline
\end{tabular}

Fonte: Thierry Philippot

O interesse das escolhas teóricas e metodológicas é possibilitar uma análise que combine o ponto de vista intrínseco, o do profissional, e o ponto de vista extrínseco, o do pesquisador, para chegar à compreensão das práticas de ensino, mobilizando, assim, três níveis de análise: um nível micro (o das microdecisões do professor no decorrer da aula), um nível meso (o da aula na sua globalidade) e um nível macro (a inscrição da prática do professor numa perspectiva temporal).

\section{Resultados e análise}

Na escola primária, a prática de ensino deve ser entendida, em primeiro lugar, na óptica do “dia
4. Tempo necessário à preparação das entrevistas. Além disso, os professores muito solicitados profissionalmente e pessoalmente nem sempre conseguem se liberar rapidamente. 
de aula”. A partir das Instruções Oficiais, o professor do primário elabora sua agenda e decide o tempo que será dedicado ao ensino de cada disciplina. Propomos, então, denominar "tempo de ensino de uma disciplina" os momentos que o professor declara dedicar a seu ensino. Nossos resultados e análises permitem apresentar algumas características do que pode ser um "tempo de ensino da Geografia"; características que são relacionadas às dificuldades e às tensões vividas pelos professores e que podem levar à marginalização dos conhecimentos escolares disciplinares.

\subsection{A importância do tempo dedicado à gestão de classe}

No conjunto dos scripts das gravações em vídeos, uma parte importante das intervenções dos docentes não correspondia a nossas categorias de análise. Essas intervenções dizem respeito à "gestão de classe" (Nault; Fijalkow, 1999), noção que remete a duas dimensões da profissionalidade docente: a capacidade de manter a ordem na sala de aula e de organizar o trabalho da classe. Consequentemente, uma parte importante das intervenções do professor não tem por objeto a regulação didática da situação de ensino-aprendizagem. Podemos, então, pensar que a "gestão de classe" se impõe aos professores como a principal finalidade da sua atividade profissional, e isso independe do contexto profissional. Desse modo, ser capaz de lidar com os considerados "alunos difíceis", gerenciar as tensões e organizar a classe, "criar um clima favorável ao trabalho", etc. são elementos preponderantes na prática de ensino; a questão dos saberes disciplinares passa, assim, a um segundo plano.

\subsection{Uma "coloração" geográfica dos tempos de ensino}

No cotidiano da sala de aula, dominado pela "lógica do fazer", esses professores propõem aos alunos tarefas que podem parecer exercícios "ritualizados" que estes devem realizar porque fazem parte de uma aula de Geografia: a partir de um documento, devem responder a um conjunto de perguntas, colorir um mapa, etc.

Nossas análises revelam também que as intervenções dos docentes, relativas aos conteúdos disciplinares, têm essencialmente como objetivos expor aos alunos conteúdos fatuais ou, a partir de um questionamento dos elementos fatuais, fazê-los buscar explicações e respostas. Esses exercícios "ritualizados" que os alunos devem realizar porque estão num período de estudo de Geografia, conferem a esses tempos de ensino o que podemos chamar de "coloração geográfica". Pela forma geral da aula e pela presença desses exercícios, um observador externo à situação reconheceria ra- 
pidamente que se trata de uma aula de Geografia. Esses "rituais" pouco relacionados à natureza mesma dos conhecimentos disciplinares a serem ensinados, constituem o que qualificamos de "revestimento disciplinar" de um tempo de ensino.

Essas características podem ser relacionadas a outras análises de práticas e de discursos dos docentes sobre suas práticas (Baillat, 2008; Philippot, 2008), as quais indicam que o conhecimento das disciplinas que eles devem ensinar é muito desigual de um professor para outro. A apropriação “superficial” do conhecimento pelos docentes traduz-se por práticas de ensino que, muitas vezes, se limitam aos aspectos mais formais, às tarefas mais “ritualizadas". Nessas aulas de Geografia, o objetivo (frequentemente implícito) dos docentes é mais transmitir conhecimentos fatuais relativos ao tema estudado do que fazer os alunos raciocinarem e construírem conceitos geográficos.

\subsection{0 tempo de ensino da Geografia: um tempo particular}

Três outras características do tempo de ensino da Geografia conduzem-nos a considerá-lo como um "tempo particular”. A primeira se baseia na relação particular dos docentes com as orientações oficiais. Estas últimas, e particularmente os parâmetros curriculares, deveriam ter um espaço importante na construção desses tempos de ensino. No caso do ensino da Geografia, pelo menos quanto ao que conseguimos detectar, as orientações oficiais parecem constituir um quadro bastante impreciso para a ação. De fato, de acordo com os docentes, o programa de Geografia está bem presente, mas é uma presença distante, é uma referência desconhecida ou pouco conhecida. Tardif e Lessard (1999) realçam que os professores não aplicam mecanicamente os currículos prescritos, mas se apropriam deles e os transformam. Por essa razão, na França, "o pouco cuidado característico dos textos oficiais dirigidos a utilizadores polivalentes” (Benoit, 1993, p. 42) pode perturbar esses mecanismos.

Nessas condições, o trabalho de apropriação e transformação das orientações curriculares, que deveriam servir de trama e de guia à atividade profissional, revela-se, então, um exercício complexo para docentes generalistas que dificilmente identificam nesse texto o objeto atual da Geografia escolar. Com isso, o exercício profissional permanece superficial. Estes seriam alguns dos tantos elementos que fazem com que os docentes procedam a uma leitura fatual do currículo, e que suas práticas de ensino visem, essencialmente, à transmissão de conteúdos fatuais.

A segunda característica está relacionada às escolhas didáticas feitas pelos do- 
centes. A análise das entrevistas de autoconfrontação coloca em evidência a importância dada, nas escolhas didáticas, aos gostos pessoais (do docente e dos alunos), como também ao prazer, por exemplo, de prolongar as trocas e as discussões com os alunos. A passagem seguinte corresponde ao momento em que, na entrevista, a professora (Senhora Har.) comenta a passagem de uma fase de discussões “informais" a uma fase de perguntas e respostas, no decorrer da qual ela aborda a noção da renda média por habitante.

O instante na aula:

\begin{tabular}{rl|}
\hline ALUNO: & $\begin{array}{l}\text { Finalmente, dizem que a França é rica, entendo, } \\
\text { mas também há pessoas que não são ricas! }\end{array}$ \\
PROFESSORA: & Ah! Escutem o que Morgane nos diz. É muito interessante!
\end{tabular}

Eis aqui o que diz a professora, em entrevista, quanto à sua decisão de chamar a atenção dos alunos para escutarem a intervenção dessa aluna:

\begin{tabular}{|c|c|}
\hline PROFESSORA: & $\begin{array}{l}\text { Achei que era muito interessante, porque a gente discutiu } \\
\text { bastante, falou, tentou ver o que era uma renda média, e } \\
\text { depois, as coisas evoluíram desse jeito, foi um pouco o ponto } \\
\text { de partida para uma fase coletiva. Com certeza. }\end{array}$ \\
\hline PESQUISADOR: & E se não houvesse esta observação da estudante? \\
\hline PROFESSORA: & $\begin{array}{l}\text { Sempre acontece, é por isso que é interessante discutir } \\
\text { com eles [...]. Podia ter durado cinco minutos a mais, cinco } \\
\text { minutos a menos também, não era algo predefinido, aliás, } \\
\text { não tinha visto o tempo passar, era a oportunidade. }\end{array}$ \\
\hline
\end{tabular}

Para esta docente, prolongar as discussões é algo agradável, o clima de trabalho na classe é descontraído, "não vi o tempo passar". Tais trocas remetem a professora à imagem de alunos ativos, participativos - indicadores que os docentes da nossa amostra mobilizam para avaliar positivamente as suas aulas. Mais importantes que 
os saberes geográficos de que os estudantes conseguiram, ou não, se apropriar, sua participação nas trocas e suas "atividades" são, aos olhos dos docentes, a expressão da eficiência de seus dispositivos de ensino.

A terceira característica, diretamente relacionada às precedentes, é aquela da duração do tempo de ensino. Quando a aula se desenvolve bem e os alunos participam, ou quando o docente não deseja iniciar rapidamente outra disciplina antes do meio-dia ou no final do dia, ele não hesita em continuar a aula na mesma disciplina, mesmo isso não tendo sido previsto inicialmente. O tempo de ensino da Geografia também aparece como um “tempo maleável”, e sua duração pode variar.

\subsection{Uma marginalização dos saberes escolares disciplinares}

Esta "construção", pelos docentes, de geografias escolares muito variadas e distanciadas da Geografia tal como apresentada nas Instruções Oficiais pode ser considerada uma expressão do domínio limitado que têm os docentes da escola primária das "matrizes disciplinares" (Develay, 1992) referentes ao conjunto das disciplinas que eles devem ensinar. Enquanto teorias da aprendizagem fortemente marcadas pelo construtivismo ou pelo socioconstrutivismo se impõem no ensino, o domínio limitado das disciplinas a serem ensinadas e a complexidade das relações dos docentes generalistas com os saberes escolares terão consequências importantes, quanto ao lugar e à função dos saberes escolares disciplinares nas práticas de ensino.

De fato, essas teorias impõem ao professor didáticas elaboradas que colocam no cerne da reflexão o processo de transmissão e apropriação dos saberes escolares e determinam uma forte focalização nesses saberes. 0 docente, então, deve ser capaz tanto de conceber situações de ensino-aprendizagem que levem em conta a diversidade dos alunos, quanto de regular essas situações. Porém, os docentes generalistas se encontram, muitas vezes, desprovidos de recursos para satisfazer tais exigências. Por essa razão, no contexto da polivalência, eles tendem a concentrar-se naquilo que, para eles, é o mais “facilmente” ensinável e oferece o menor risco possível: a concepção e a realização de aulas que visam à transmissão de fatos geográficos. Então, os elementos mais complexos: conceitos, raciocínio geográfico, etc. não serão sequer abordados.

Também se vê, na busca da motivação e da participação dos alunos, outra consequência dessas teorias que, talvez, nem sempre sejam bem compreendidas pelos docentes. Para estes, esta "atividade" dos alunos torna-se um fim em si mesma. É, de certa maneira, a garantia de aprendizagem. A ideia segundo a qual é necessário fazer 
os alunos participarem se impõe, independentemente da questão dos saberes escolares a serem construídos. E isso pode levar o docente a ignorar práticas de ensino pertinentes, de um ponto de vista didático, mas que, para ele e na classe, implicariam na falta de participação dos alunos.

Enfim, se os docentes da nossa amostra estão preocupados com as aprendizagens que os seus alunos possam realizar, nossas análises levam a pensar, pelo menos no que tange à Geografia, que eles estariam pouco preocupados com as aprendizagens - conceitos, noções, reflexões - em Geografia. A Geografia ensinada, tal como pudemos constatar e analisar, traduz uma "profissionalidade" docente marcada mais pela vontade de levar os alunos a adquirir habilidades "transversais" de saber-fazer - saber identificar, ler e extrair informações de um “documento”, saber trabalhar em grupo, etc. - do que pelo desejo de que dominem conteúdos disciplinares específicos. 0 ensino da Geografia seria, de certa maneira, um pretexto ou um contexto para construir competências transversais.

\section{Conclusão}

Para os nove docentes da nossa amostra, a dimensão didática está pouco presente em suas práticas de ensino no cotidiano da classe. Essa Geografia que se está construindo exprime o encontro, no âmbito da sala de aula, das prescrições oficiais, das concepções de um docente, das suas dificuldades em ser "excelente" em todas as disciplinas e das interações com os alunos. Ela traduz as dificuldades de docentes generalistas para ensinar uma disciplina de cujo objeto, de cujos trâmites e de cujas finalidades eles não têm uma imagem precisa. 0 ensino da Geografia constitui, então, um tempo escolar particular; um tempo de "liberdades profissionais" que difere daquele do ensino das matérias "fundamentais", como se o docente tivesse o sentimento de uma responsabilidade profissional inferior em relação ao ensino dessa disciplina.

Preocupados com o bom resultado das suas aulas e com o êxito (talvez somente aparente?) dos seus alunos, os nove docentes têm práticas de ensino de Geografia que ressaltam mais a lógica da realização, “o fazer”, do que a lógica da compreensão, “para que fazer?”. Assim, os saberes escolares disciplinares dão pouco o tom às práticas de ensino desses docentes da escola primária. Eles parecem estar, mesmo, à margem dessas práticas. São tantos elementos, que questionam a própria perenidade das disciplinas escolares na escola primária. 


\section{Referências bibliográficas}

AMIGUES, R. Le travail enseignant: prescriptions et dimensions collectives de l'activité. Les Sciences de l'éducation-Pour l'ère nouvelle, v. 42, n. 1, p.11-26, 2009.

AMIGUES, R. Pour une approche ergonomique de l'activité enseignante. Skholê, n. 1, p. 5-16, 2003. Disponível em: 〈http://recherche.aix-mrs.iufm.fr/publ/skhole/pdf/o3. HS1.5.pdf〉. Acesso em: 20 nov. 2010.

AUDIGIER, F. Sur la didactique de la géographie. Thèses de printemps (cru 1993). Géographes Associés, n. 12, p. 52-58, 1993.

AUDIGIER, F. Les représentations de la géographie dans l'enseignement primaire en France: Habitat commun, voisinage et distances. Cahier de géographie du Québec, v. 43, n. 120, p. 395-412, 1999.

AUDIGIER, F.; TUTIAUX-GUILLON, N. (Org.). Regards sur l'histoire, la géographie et l'éducation civique à l'école élémentaire. Paris: INRP, 2004.

BAILLAT, G. Enquête sur la polyvalence des enseignants du premier degré. Reims: IUFM de Champagne-Ardenne, 2001. Rapport de recherche.

BAILLAT, G. Les enseignants du primaire et les savoirs scolaires: quelles pratiques de classe? Reims, IUFM Champagne-Ardenne, 2008. Rapport de recherche.

BAILLAT, G. Polyvalence, conceptions didactiques et partage du travail chez les enseignants du premier degré. Reims: IUFM de Champagne-Ardenne, 2003. Rapport de recherche.

BENOIT, $M$. Ecole primaire: de l'importance de la rédaction des programmes pour une mise en œuvre efficace. Géographes Associés, n. 12, p. 34-42, 1993.

BLAT GIMENO, J. L'échec scolaire dans l'enseignement primaire: moyen de le combattre. Paris: Unesco, 1984.

CHERVEL, A. L'histoire des disciplines scolaires. Réflexions sur un domaine de recherche. Histoire de l'éducation, n. 38, p. 59-119, maio 1988.

CLOT, Y. et al. Entretiens en autoconfrontation croisée: une méthode en clinique de l'activité. Pistes, v. 1, n. 1, p. 1-7, 2000. Disponível em: 〈http://www.pistes.uqam.ca/ v2n1/sommaire.html>. Acesso em: 4 dez. 2010.

DEVELAY, M. De l'apprentissage à l'enseignement. Paris: E.S.F, 1992.

DURAND, M. Analyse du travail dans une visée de formation: cadres théoriques, méthodes et conceptions. In: BARBIER, J.-M. et al. (Org.), Encyclopédie de la Formation. Paris: Presses Universitaires de France, 2009. p.827-856.

FRANCE. M.E.N.: Ministère de l'Education Nationale. I.G.E.N: Inspection Générale de l'Education Nationale. Sciences expérimentales et technologie, histoire et géographie. Leur enseignement au cycle III de l'école primaire. Rapport n. 2005-112. Paris, 2005. 
FRANCE. M.E.N: Ministère de l'éducation Nationale, de l'Enseignement supérieur et de la Recherche. Horaires et programmes d'enseignement de l'école primaire. Bulletin officiel, n. 3, 2008.

GOIGOUX, R. Analyser l'activité d'enseignement de la lecture: une monographie. $R e$ vue Française de Pédagogie, n. 138, p.125-134, 2002.

LANG, V. La professionnalisation des enseignants. Paris: Presses Universitaires de France, 1999.

LENOIR, Y. et al. La stratification des matières scolaires chez les enseignants du primaire au Québec: évolution ou stabilité des représentations depuis 1981. Revue des Sciences de l'Education, n. 3, p. 483-514, 2000.

MAROY, C. Les évolutions du travail enseignant en France et en Europe: facteurs de changement, incidences et résistances dans l'enseignement secondaire. Revue Française de Pédagogie, n. 155, p. 111-142. 2006.

MUCCHIELLI, A. (Org.). Dictionnaire des méthodes qualitatives en sciences humaines. 3. ed. Paris: Armand Colin, 2009.

NAULT, T. ; FIJALKOW, J. La gestion de classe : d'hier à demain. Revue des sciences de l'éducation, 1999, v. 25, n. 3, p. 451-466.

NICLOT, D.; PHILIPPOT, T. Les ambiguïtés du rapport aux savoirs disciplinaires des maîtres polyvalents du primaire en France: l'exemple de l'histoire - géographie. In: BAILLAT, G.; HASNI, A. (Org.). La profession enseignante face aux disciplines scolaires: le cas de l'école primaire. Sherbrooke: Editions du CRP, 2008. p. 185-216.

PASTRÉ, P. Introduction. In: Lenoir, Y.; Pastré, P. (Org.), Didactique professionnelle et didactiques disciplinaires en débat. Toulouse: OCTARES, 2008. p.13-17.

PHILIPPOT, T. La professionnalité des enseignants de l'école primaire: les savoirs et les pratiques. 2008. Tese (Doutorado) - Université Reims Champagne-Ardenne, Reims.

TARDIF, M.; LESSARD, C. Le travail enseignant au quotidien. Expérience, interactions humaines et dilemmes professionnel. Bruxelles: De Boeck Université, 1999.

WITTORSKI, R. La professionnalisation. Savoirs, n. 17, p.11-36, 2008.

YVON, F.; CLOT, Y. Apprentissage et développement dans l'analyse du travail enseignant. Psicologia da Educação, São Paulo, n. 19, p. 11-38, 2004.

Recebido em 3 de abril de 2012 e aprovado em 17 de agosto de 2012. 